\title{
Vulnerabilidade do aquífero Serra Geral à contaminação no município de Erechim - Rio Grande do Sul - Brasil
}

\author{
Vulnerability of the Serra Geral aquifer to contamination in the city of Erechin
}

\author{
José Luiz Silverio da Silva', Leônidas Luiz Volcato Descovi Filho², Raquel Paula Lorensi³, \\ Jussara Cabral Cruz ${ }^{4}$, Flávio Luiz Foletto Eltz ${ }^{5}$
}

\begin{abstract}
1. Geólogo, Departamento de Geociências - UFSM ; 2, Doutorando em Geografia, UFSC ${ }^{3}$, professora da Universidade Regional Integrada do Alto Uruguai e das Missões, Brasil; 4, Professor Associado da UFSM, Brasil ; 5 . Revista Brasileira de Ciência do Solo . Professor e Pesquisador do CCR/ UFSM aposentado
\end{abstract}

\section{Resumo}

A porção da Região Hidrográfica do Rio Uruguai, situada entre os estados do Rio Grande do Sul e Santa Catarina, vem sendo avaliada como potencial de recursos hídricos para empreendimentos hidroelétricos. O município de Erechim está localizado entre as coordenadas $27^{\circ} 29^{\prime} 20^{\prime \prime}$; 5 52 $10^{\prime} 03^{\prime \prime} \mathrm{W}$ e $27^{\circ} 47^{\prime} 15^{\prime \prime}$ ' $; 5^{\circ} 21^{\prime} 52^{\prime \prime} \mathrm{W}$ na região noroeste do estado. E faz parte dos derrames vulcânicos da Formação Serra Geral, Fácies Paranapanema na Bacia do Paraná. Os usos das águas subterrâneas na Região Hidrográfica do Uruguai são múltiplos: abastecimento humano, animal, irrigação, estâncias hidrominerais termais, engarrafamento de águas minerais. Entretanto, o risco de contaminação das águas subterrâneas vem crescendo junto com a sua demanda, fato que indica a necessidade de gestão desse recurso. Este trabalho tem como objetivo avaliar e espacializar em cartogramas o índice de vulnerabilidade à contaminação do Sistema Aquífero Serra Geral/SASG aflorante que forma um aquífero fissural livre. De um total de 99 poços tubulares cadastrados no Sistema de Informação de Águas Subterrâneas SIAGAS/CPRM, aplicou-se o método GOD em 55 poços. Os cartogramas foram gerados no aplicativo Surfer 8.0 e ArcGIS 9.3, representados no Sistema Universal Transversa de Mercator/UTM. O índice de vulnerabilidade à contaminação apresentou 47 poços inseridos na classe de vulnerabilidade média, representando cerca de $85,5 \%$ da área total avaliada de $430,76 \mathrm{~km}^{2}$. A classe baixa ocupou $12,7 \%$ da área e apenas $1,8 \%$ inseriu-se na classe insignificante. A faixa de variação da cota potenciométrica foi entre 416 e 780 metros, observando-se a ocorrência de altos potenciométricos regionais e baixos locais. A direção regional de fluxo subterrâneo foi no sentido sudeste - nordeste neste trecho contribuindo para a calha do Rio Uruguai.

Palavras-chave: águas subterrâneas, SIG, espacialização

\begin{abstract}
The portion of the Hydrographic Region of Uruguay River situated between the Rio Grande do Sul and Santa Catarina states are being evaluated as potential of hydric resources for hydroeletric enterprises. The City of Erechim is located between the coordinates $27^{\circ} 29^{\prime} 20^{\prime \prime} \mathrm{S} ; 52^{\circ} 10^{\prime} 03^{\prime \prime} \mathrm{W}$ and $27^{\circ} 47^{\prime} 15^{\prime \prime} \mathrm{S} ; 52^{\circ} 21^{\prime} 52^{\prime \prime} \mathrm{W}$, northwest region of the state, is part of the volcanic spills of the Serra Geral Formation, Fácies Paranapanema in the Paraná basin. The uses of ground waters in the Hydrografic Region of Uruguay are multiple: human, animal supplying, hydrothermal waters, irrigation, mineral water bottling. However, the risk of contamination of ground waters comes together with its growing demand, fact that indicates the necessity of this resource management. This work has as objective to evaluate and to spatialize in cartograms GOD system for evaluation of aquifer pollution vulnerability of the Serra Geral Aquifer System/SASG, forming one unconfined fissural aquifer at outcrops near surface. Of a total of 99 tubular wells registered in cadastre in the System of Ground Water Information SIAGAS/CPRM, the GOD system for evaluation of aquifer pollution vulnerability was applied in 55 wells. The cartograms had been generated in the software 8.0 Surfer and ArcGIS 9.3, represented in the Universal System Transversa de Mercator/UTM. The GOD system for evaluation of aquifer pollution vulnerability showed 47 wells inserted in the class of average vulnerability, representing about $85.5 \%$ of the total area evaluated of $430.76 \mathrm{~km}$ ${ }^{2}$. The class low occupied $12.7 \%$ of the area and only $1.8 \%$ were inserted in the negligible class. The layer of variation of the potenciometric quota was between 416 and 780 meters, being observed the occurrence of high regional potenciometrics and low potenciometrics locals. The regional direction of underground flow was in the direction southeast - northeast, for the gutter of the Uruguay River. .
\end{abstract}

Keywords: groudwaters, GIS, espacialization. 


\section{INTRODUÇÃO}

Na superfície da Terra, cerca de $97 \%$ da água existente está na forma de água salgada e o restante na forma de água doce. A reserva de água disponível viável para o consumo humano restringe-se somente àquela parcela que se encontra na forma de água superficial e água subterrânea, que representa apenas $0,7 \%$ da água doce existente na superfície da Terra (HASSUDA, 1999). A contaminação, quando ocorre, é muito mais lenta e os custos para recuperação podem ser proibitivos (FOSTER e HIRATA, 1993).

Sorando in Llera e Azcoiti (2008) diz que:

"as águas subterrâneas constituem um recurso básico para uma elevada porcentagem da população mundial. São muitas as áreas do Planeta Terra em que, tanto a subsistência humana como a manutenção dos ecossistemas naturais, estão indissoluvelmente ligadas a este recurso. Como resultado do assentamento de populações, em ocasiões ultrapassando a capacidade do território em acolhê-las, a quantidade e a qualidade da água subterrânea se encontra em muitos locais ameaçada por uma intensiva explotação, assim como em determinadas atividades agrícolas e industriais que contribuem a sua contaminação".

Por outro lado, Ronen et al. (2000 e 2005) estudaram o aquífero freático Costeiro de Israel, constituído por rochas sedimentares clásticas e chamam a atenção para uma região de interface entre a zona não saturada (vadosa) e a zona saturada denominada de Saturated and Unsaturated Interface Region/SUIR. Relataram, também, uma flutuação de cerca de três metros para a SUIR e estimaram que o tempo de residência de sua recarga poderia ser superior a cinco anos.

A região Hidrográfica do Uruguai está inserida na Bacia do Paraná, entre a divisa dos estados do Rio Grande do Sul e Santa Catarina, a qual vem sendo buscada como fonte de energia elétrica para vários empreendimentos, tais como: Itá (1.450 MW), Machadinho (1.150 MW), Foz do Chapecó (855 MW), além de várias Pequenas Centrais Hidroelétricas/PCHs. Maciel Filho et al. (2005) apresentam aspectos geológicos para inventário, na seleção ambiental de barragens. A área deste estudo compreende o município de Erechim, situado no Planalto da Serra Geral, composto por uma sequência de derrames de rochas vulcânicas da Formação Serra Geral.
A área em estudo é parte do projeto FRAG-RIO (CRUZ et al., 2010 e CRUZ et al. 2013), realizado entre a UNIPAMPA, UFSM e SRU/MMA e que busca desenvolver metodologias para avaliação dos impactos ambientais de empreendimentos hidroelétricos que alteram o meio ambiente. Dentre os aspectos avaliados estão: a geologia e geomorfologia; a estabilidade de encostas, a fragilidade à erosão, as áreas de mineração e a contaminação das águas. Os valores variam de 1 (máxima fragilidade) até 255 (fragilidade mínima). Na variável geologia/ geomorfologia, são considerados aspectos relativos às águas subterrâneas, avaliando-se a fragilidade relativa à variável cota potenciométrica e a fragilidade relativa à zona vadosa versus lineamentos e lavra de águas minerais. Estas informações estão disponíveis nos dois estados na mesma escala de representação (1:250.000). Como essa metodologia de avaliação de fragilidades ainda encontra-se em fase de desenvolvimento, seus resultados não serão aqui discutidos. Nesse artigo, será utilizado o método GOD (FOSTER e HIRATA, 1988, 1993), (FOSTER et al., 2006) para avaliação do aquífero à contaminação. Este método simples é amplamente aceito pela comunidade hidrogeológica, uma vez que utiliza apenas três parâmetros e pode espacializar zonas de diferentes classes de contaminação.

Assim, o objetivo desse trabalho é de espacializar em cartogramas e mapas o índice de vulnerabilidade natural do aquífero à contaminação no município de Erechim, seus lineamentos e tentativamente, sua potenciometria, indicando as tendências de fluxo subterrâneo em aquíferos livres superficiais.

A Companhia Riograndense de Saneamento (CORSAN), visando resolver os problemas de abastecimento humano, no ano de 2005, licitou a perfuração de um poço tubular profundo na estação de tratamento de águas na área municipal de Erechim. Este atingiu a profundidade de 929 metros e penetrou o Sistema Aquífero Serra Geral/SASG e também o Sistema Aquífero Guarani/SAG na cota de 868m (poço ID4300016899) (CREA, 2005; BRASIL/CPRM/ SIAGAS, 2010).

De acordo com Rebouças e Fraga (1988), os mecanismos de recarga do Aquífero Serra Geral ocorrem preferencialmente por dois condicionamentos distintos: a) através da infiltração de águas meteóricas conduzidas através das rupturas tectônicas regionais, cobertas por manto de alteração e/ ou solos; e b) a partir da infiltração de água armazenada nas coberturas sedimentares pós-basálticas representadas no Estado do Rio Grande do Sul pela Formação Tupanciretã BRASIL/CPRM (2008), a qual não ocorre na área deste estudo.

O estudo de Hausman (1995) salienta que a 
circulação da água subterrânea no Aquífero Serra Geral é marcada por dois aspectos: uma circulação horizontal no manto de alteração e outra associada à rocha reservatório propriamente dita.

Nanni et al. (2005) avaliaram os aspectos de vulnerabilidade natural associados ao risco de contaminação do Aquífero Serra Geral através da atividade com suinocultura na Região das Missões/ RS (Método 30) na área de abrangência da bacia hidrográfica dos rios Turvo, Santa Rosa e Santo Cristo, pertencentes a Região Hidrográfica do Rio Uruguai, Estado do Rio Grande do Sul (SEMA, 2004).

Mocellin \& Ferreira (2009) realizaram estudos da conectividade e compartimentação dos sistemas aquíferos Serra Geral e Guarani no Sudoeste do Estado do Paraná, onde avaliaram a potenciometria, vazão e capacidade específica de exploração de 181 poços tubulares.

O termo vulnerabilidade das águas subterrâneas começou a ser usado primeiramente por Le Grand (1964) nos Estados Unidos da América e por Margat (1968) na França. Na década de 1980, foi mais amplamente utilizado por vários autores (ALLER et al., 1987; FOSTER, 1987; FOSTER e HIRATA, 1988; FOSTER et al., 2006) e nos anos 90 por autores como Civita (1990).

Já na década de 1970, na França (ALBINET e MARGAT, 1970) utilizou-se termo vulnerabilidade sem preocupação com sua definição e de maneira mais ampla na década de 1980 (HEATH, 1983; ALLER et al., 1987; FOSTER e HIRATA, 1988). Embora se referissem à suscetibilidade relativa dos aquíferos à contaminação antropogênica, o termo inicialmente era usado sem nenhum objetivo de definição formal.

Existem vários métodos para avaliação e espacialização da vulnerabilidade à contaminação de aquíferos, entre eles a metodologia GOD, desenvolvida por Foster e Hirata (1988) e Foster et al. (2006), adaptada para as condições brasileiras. Outras metodologias existentes são: a) DRASTIC, de Aller et al. (1987), a qual utiliza vários parâmetros; b) SINTACS, considerada uma derivação da DRASTIC (CIVITA, 1990); c) AVI (VAN STEMPVOOR et al., 1994), uma metodologia sensível, mas que requer o conhecimento da espessura e a condutividade hidráulica das camadas que sobrepõem o aquífero; d) PATHS (ORTEGA e MIRANDA, 2004), desenvolvida para aquíferos cubanos.

O método GOD é muito sensível, fácil de aplicar em condições de escassas informações (ORTEGA e MIRANDA, 2004), como no caso avaliado do município de Erechim no Estado do
Rio Grande do Sul. O abastecimento público do município de Erechim é executado pela Companhia Riograndense de Saneamento (CORSAN), com uma parcela explotada do SASG e outra de captações superficiais (ETA, Arroio Ligeirinho). Este fato demonstra a importância de estudos em escala local do poço e também regional de Bacia Hidrográfica, os quais buscam subsidiar ações para proteção dos recursos subterrâneos e/ou ampliação do conhecimento do meio físico associado aos licenciamentos ambientais de empreendimentos hidroelétricos na Bacia Hidrográfica do Rio Uruguai entre os Estados do Rio Grande do Sul e Santa Catarina.

\section{Caracterização da Área}

A área em estudo está localizada no município de Erechim, no Norte do Estado do Rio Grande do Sul (Figura 1). Este município apresentava uma população estimada para o ano de 2009, de cerca de 97.916 habitantes (BRASIL/IBGE, 2009). Destes, $90,8 \%$ habitam a zona urbana, enquanto que apenas $9,2 \%$ moram na zona rural. Nesta região, desenvolvem-se atividades agrícolas (cultivo de soja, milho) e agropecuária extensiva. Sua área é de $430,76 \mathrm{~km}^{2}$, representando cerca de $0,16 \%$ da área total do Estado Rio Grande do Sul.

A área urbana municipal está localizada em cotas altimétricas da ordem de 800 metros acima do nível médio do mar. Situa-se aproximadamente no interflúvio de duas bacias hidrográficas pertencentes à região Hidrográfica do Rio Uruguai (U), Bacia do Passo Fundo Várzea (U-020) e a Bacia do Apuaê-Inhandava (U-020) Figura 1 Estado do Rio Grande do Sul/SEMA (2004).

Em termos climáticos, a região está situada na Zona Temperada, possuindo clima Mesotérmico brando super-úmido sem seca, o qual apresenta chuvas distribuídas por todo ano, verões quentes, invernos frios e sua média anual de precipitações em torno de 1.700 mm (PIRAN, 1982; RAMPAZZO, 2003). Hausman (1995) estimou para a região uma precipitação média anual de cerca de $1.800 \mathrm{~mm}$.

Streck et al. (2008) classificaram os solos como Latossolo Vermelho aluminoférrico típico (Unidade Erechim). Estes são bem drenados, normalmente, profundos a muito profundos e apresentam em seu perfil uma sequência de horizontes A, $\mathrm{Bw}-\mathrm{C}$, onde o horizonte $\mathrm{Bw}$ é do tipo B latossólico. Em alguns casos, os solos podem ser pouco profundos associados com inclusões de Neossolos Regolíticos ou Litólicos. Os solos formam horizontes homogêneos e muito intemperizados, têm 


\section{Localização dos poços no Município de Erechim/RS}

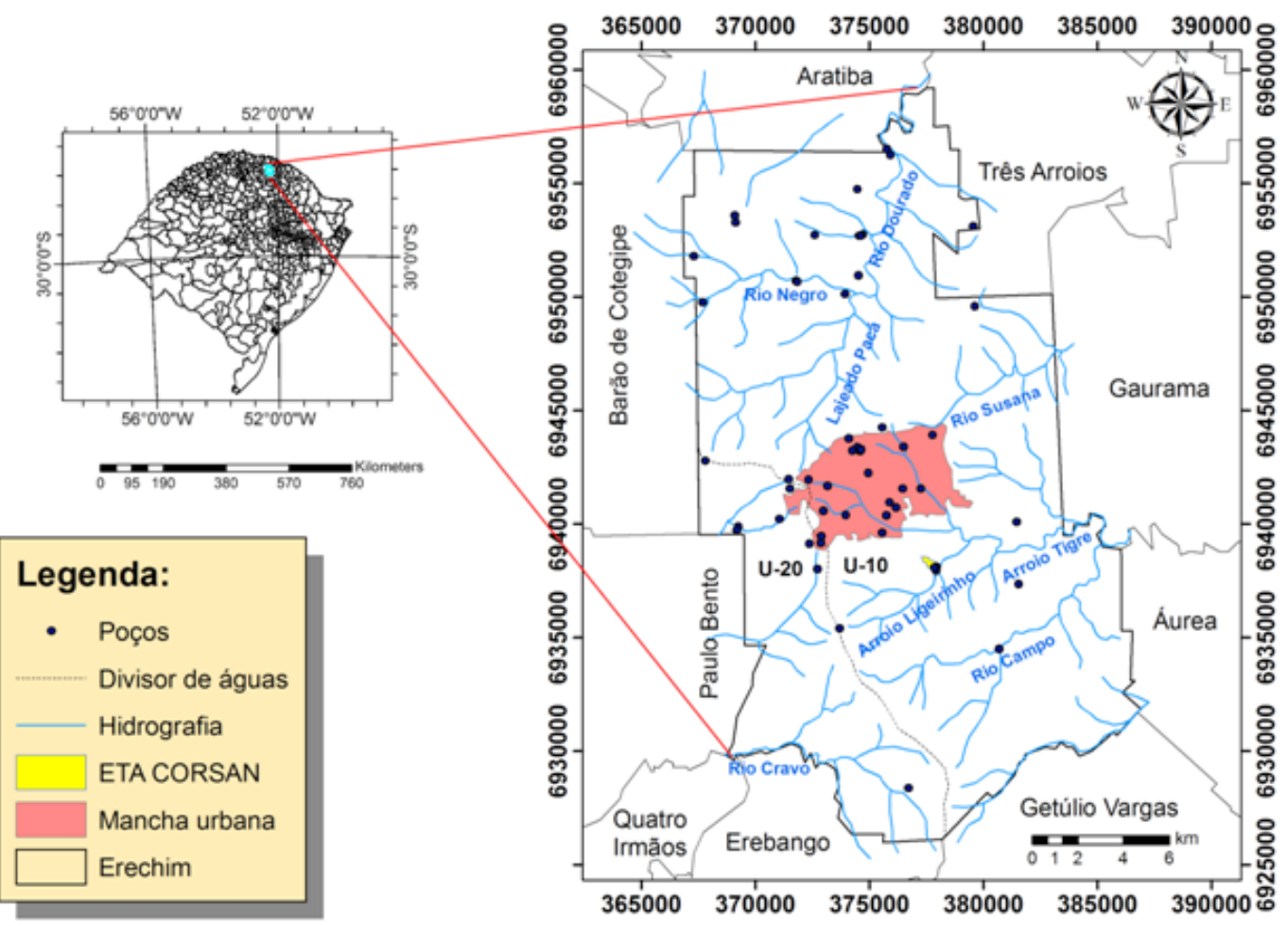

Figura 1 - Mapa do Estado Rio Grande do Sul, Brasil com detalhe da localização dos 55 poços tubulares no município de Erechim/RS.

predomínio de caulinita e óxidos de ferro, o que lhe confere uma baixa capacidade de troca catiônica/CTC. Estes solos profundos e bem drenados funcionam como um aquífero livre.

\section{Geologia e Hidrogeologia}

No ano de 1966, Hausman apresentou um esboço hidrogeológico das áreas basálticas no Rio Grande do Sul, classificando os aquíferos com base na produtividade nos basaltos. Hausman (1995) apresentou as Províncias e Sub-províncias do Estado do Rio Grande do Sul, considerando os derrames de rochas vulcânicas na Província Basáltica e Sub-província do Planalto. Nesse trabalho, o autor afirma que a circulação das águas subterrâneas na Província Basáltica é marcada por dois aspectos: uma circulação horizontal no manto de intemperismo e outra associada à rocha propriamente dita. A circulação ocorre próximo ao contato entre a zona vadosa com a rocha pouco alterada ou sã (Neossolo Litólico). Geralmente, este acúmulo de água propicia a formação de um aquífero livre de importância fundamental para recarga do aquífero fraturado em posição mais profunda, bem como se reflete também na maior facilidade de circulação no meio, resultando num maior risco de alteração da qualidade natural da água subterrânea nela contida. Estimou um volume anual de águas infiltradas para o aquífero da ordem de 100 a $200 \mathrm{~mm} /$ ano.

Observando-se os perfis geológicos da área de estudo disponíveis no (BRASIL/CPRM/SIAGAS, 2010), notou-se uma maior concentração de entradas de água nas perfurações, em profundidades variando entre 50 e $100 \mathrm{~m}$.

As entradas mais próximas da superfície do terreno não apresentaram uma frequência muito alta, o que torna as condições de ocorrência da água freática com um menor risco intrínseco à alteração da sua qualidade natural sob condições antrópicas de uso e ocupação do solo. Apenas duas entradas de água ocorreram em profundidades superiores aos 200 m Figura 2.

Deve-se ressaltar que o tipo litológico predominante no município de Erechim apresenta, 


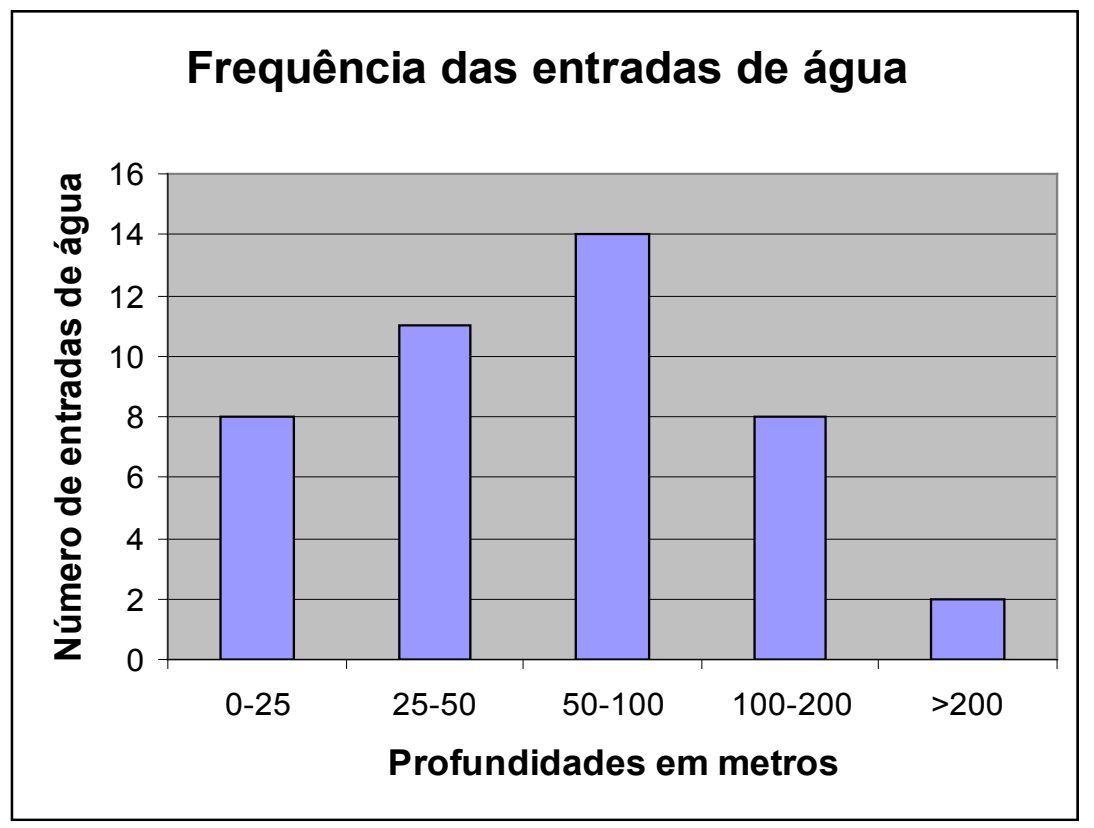

Figura 2 - Frequência das entradas de água em 22 poços com informações no BRASIL/CPRM/SIAGAS (2010) no município de Erechim/RS/Brasil.

em vários locais, um baixo nível de intemperismo, sendo, portanto, as rochas vulcânicas utilizadas na mineração de basalto na forma de brita. Foi observado nos processos do DNPM a ocorrência de três solicitações de lavra de águas minerais (BRASIL/ DNPM/SIGHIDRO, 2010). Deve-se salientar que a Região Hidrográfica do Uruguai apresenta um potencial hidrotermal, captado através de poços

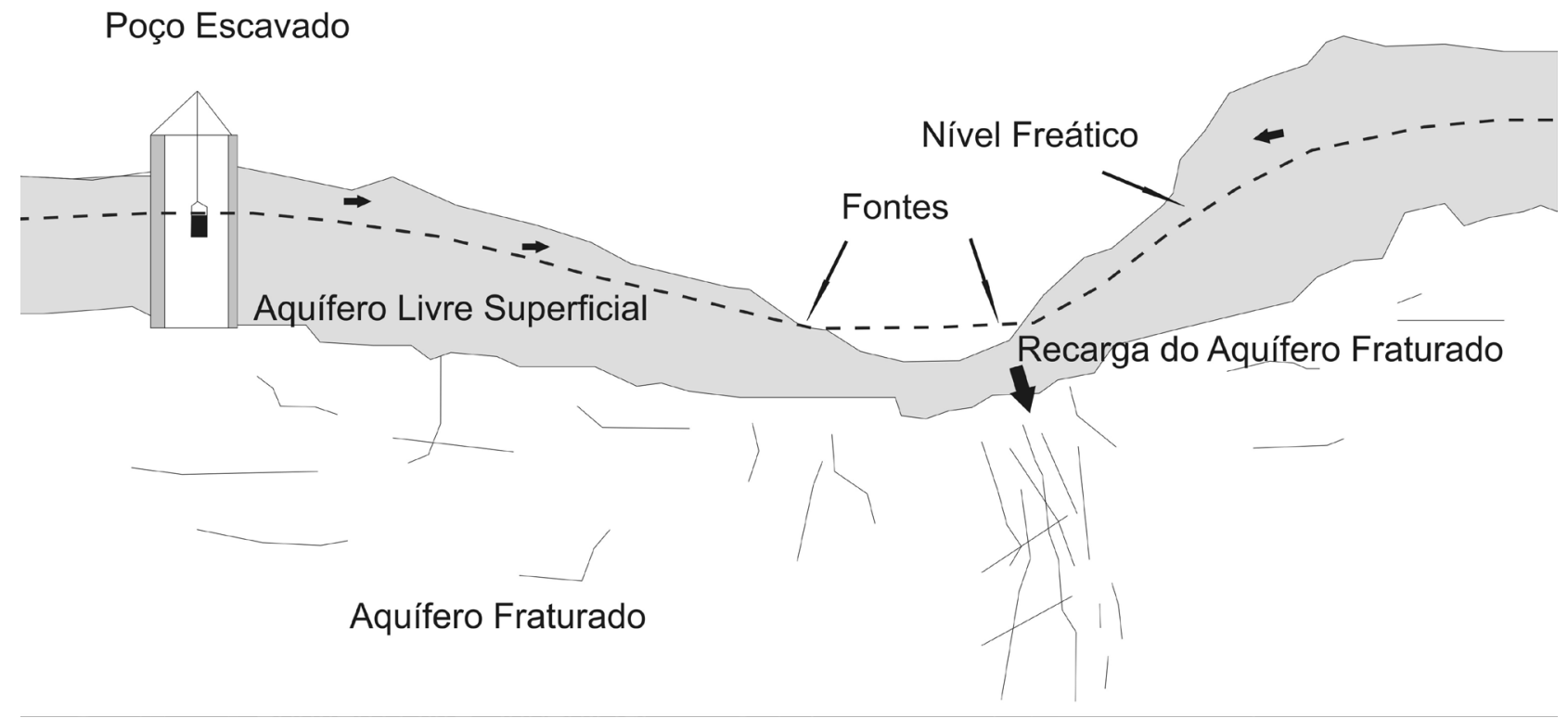

Figura 3 - Esquema da ocorrência do aquífero livre no manto de alteração das rochas vulcânicas e sua relação com o aquífero fraturado subjacente. Fonte: Nanni et al. (2005). 
tubulares, que explotam águas do SAG, confinado profundo. Este vem sendo utilizado em diversas estâncias hidrominerais: São João do Oeste, Palmitos, Itá e Piratuba no Estado de Santa Catarina e no Estado do Rio Grande do Sul; Três Arroios, Marcelino Ramos, Iraí.

No cadastro da CPRM, o poço (ID 4300013499) de Três Arroios, localizado a cerca de $20 \mathrm{~km}$ do município de Erechim, apresenta características hipotermais com temperatura da ordem de $33,2^{\circ} \mathrm{C}$ (BRASIL/DNPM /SIGHIDRO, 2010). Esta perfuração penetrou cerca de 400 metros de rochas vulcânicas da Formação Serra Geral (Domínio 5) e atingiu o teto dos arenitos da Formação Botucatu em cerca de 401 metros até uma profundidade de 1000 metros, Domínio 2 (BRASIL/CPRM, 2007). Este poço, confinado profundo com uso hidrotermal, apresenta vários elementos químicos fora dos padrões para consumo humano, apresentando concentrações anômalas de flúor (SILVÉRIO DA SILVA et al., 2008).

O município de Erechim situa-se no Planalto da Serra Geral e faz parte da Bacia do Paraná, Província Paraná, Grupo São Bento, composta por uma seqüência de derrames de rochas vulcânicas pertencentes à Formação Serra Geral. Faz parte da fácies Paranapanema (BRASIL/CPRM, 2008), constituída por derrames basálticos granulares finos, melanocráticos, contendo esta fácies horizontes vesiculares espessos preenchidos por quartzo (ametista), zeólitas, carbonatos, celadonita, cobre nativo e barita. A porção Noroeste compreende a maior concentração de jazidas de ametista do estado do Rio Grande do Sul. Já o SAG é constituído por arenitos da Formação Botucatu em condição de confinamento profundo.

Por exemplo, o poço identificado no SIAGAS/CPRM (ID 4300016899) penetrou cerca de 868 metros de rochas vulcânicas pertencentes a Formação Serra Geral/ Domínio 5 (rochas vulcânicas) (BRASIL/CPRM, 2007) ou ainda ao Sistema Aquífero Serra Geral (MACHADO e REITAS, 2005). Ainda penetrou cerca de 61 metros em arenitos pertencentes a Formação Botucatu/ Domínio 2 (Bacias Sedimentares) (BRASIL/CPRM, 2007). Neste cadastro, este poço foi considerado semi-confinado e apresentou vários elementos químicos, incluindo o flúor fora dos valores máximos permissíveis/VMP Portaria $n^{\circ}$ 518/2004 para abastecimento humano. Atualmente, encontra-se em situação bombeando e sua água é misturada a corpo de águas mantendo assim a qualidade compatível para consumo humano.

De acordo com (MACHADO e FREITAS, 2005), a região de Erechim insere-se no Sistema
Aquífero Serra Geral I, o qual ocupa a parte centro-oeste da região dominada pelos derrames da Unidade Hidroestratigráfica Serra Geral no planalto rio-grandense. Constitui-se principalmente de litologias basálticas, amigdalóides e fraturadas pertencente ao Domínio Hidrogeológico 5 = Vulcânicas (BRASIL/CPRM, 2007). Este aquífero apresenta uma possibilidade entre média a alta a média de águas subterrâneas em rochas de porosidade por fraturas. $\mathrm{O}$ aquífero constitui-se de litologias basálticas, amigdalóides e fraturadas, capeadas por solo espesso avermelhado. Predominam poços com capacidades específicas entre 1 a $4 \mathrm{~m} 3 / \mathrm{h} / \mathrm{m}$ excepcionalmente superiores a $4 \mathrm{~m} 3 / \mathrm{h} / \mathrm{m}$.

A Figura 3 ilustra um corte esquemático no SASG idealizado por (NANNI et al., 2005), o qual mostra conexão entre o aquífero livre superficial e o aquífero fissural profundo penetrados por 55 captações. Destas, cerca de $49 \%$ apresentam profundidade final variando entre 4 até 100 metros (BRASIL/CPRM/SIAGAS, 2010).

\section{Material e métodos}

Landim (2000) apresentou uma introdução aos métodos de estimação espacial para a confecção de mapas e em Landim e Queiroz (2000) foi apresentada uma análise estatística de dados geológicos multivariados. A aplicação do Programa SURFER na espacialização de parâmetros geológicos pode ser observada em Landim et al. (2002) e em Landim e Sturaro (2002). Já Zingano (2005) salienta ser o SURFER um programa de interpolação para gerar curvas de isovalores e superfícies, baseado em um grid. Este programa é utilizado para espacializar as cotas potenciométricas e o índice de vulnerabilidade à contaminação do aquífero.

Para o desenvolvimento do trabalho, os dados foram extraídos do Sistema de Informação de Águas Subterrâneas (SIAGAS), da Companhia de Pesquisa e Recursos Minerais (CPRM), disponíveis na página eletrônica (http://www.cprm.gov.br). Esta permite o acesso a um banco de dados que disponibiliza informações de captações através de poços cadastrados de todo o Brasil. A presente pesquisa informando o estado, o município e o número do poço, sendo possível obter as informações cadastrais, o perfil geológico do poço, parâmetros hidráulicos, físico-químicos e ainda gerar arquivos para download. Até abril de 2010, no município estudado haviam 99 poços cadastrados no SIAGAS/CPRM.

Para o cálculo do índice de vulnerabilidade foi utilizado o método GOD, desenvolvido por (FOSTER e HIRATA, 1993), o qual leva em consi- 
deração: a) o tipo de ocorrência da água subterrânea (ausente, surgente, confinado, semi-confinado e não confinado (coberto), e não confinado); b) as características de litologia e grau de consolidação dos estratos acima da zona saturada (não consolidadas - sedimentos, e consolidadas - rochas porosas e rochas compactas; c) a profundidade do nível freático ou o teto do aquífero confinado $(<5$ m, 5 - $20 \mathrm{~m}, 20-50 \mathrm{~m} \mathrm{e}>50 \mathrm{~m})$.

Segundo (FOSTER e HIRATA, 1993), a metodologia GOD é fundamentada em dados pré-existentes, ou seja, atribui-se valores a três tipos de parâmetros. "G" avalia o grau de confinamento hidrológico, "O" ocorrência do substrato sobrejacente se relaciona com as características litológicas e grau de consolidação da zona saturada ou camadas confinantes (livre, confinado e semi-confinado) e "D" a profundidade da água subterrânea. O índice de vulnerabilidade do aquífero à contaminação é obtido pelo produto entre os três parâmetros avaliados. A Figura 4 ilustra os passos para a aplicação do Sistema GOD (FOSTER et al., 2006) o qual explica como se calcula o índice de vulnerabilidade à contaminação do aquífero. São necessárias informações mínimas desses três parâmetros para a aplicação do método.

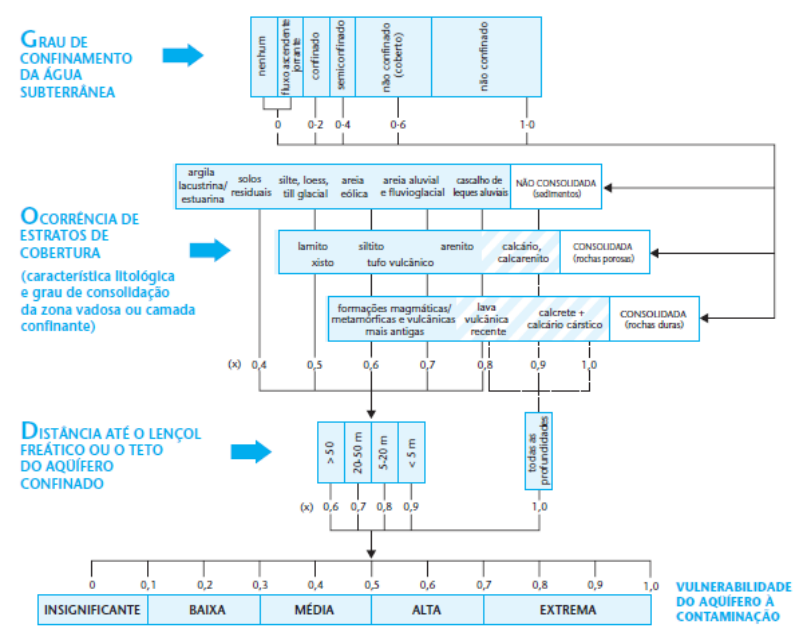

Figura 4 - Sistema GOD para avaliação da vulnerabilidade do aquífero à contaminação Foster et al. (2006).

O índice de vulnerabilidade do aquífero à contaminação pode ser obtido através da equação 1

Equação 1

$$
I V=G^{*} O^{*} D \quad \text { O índice de }
$$

vulnerabilidade à contaminação é expresso em valores distribuídos em um intervalo variando entre 0 até 1 . A Figura 5 ilustra o sistema GOD aplicado ao poço (ID 4300016899 SIAGAS/CPRM), indicativa da classe de vulnerabilidade baixa.

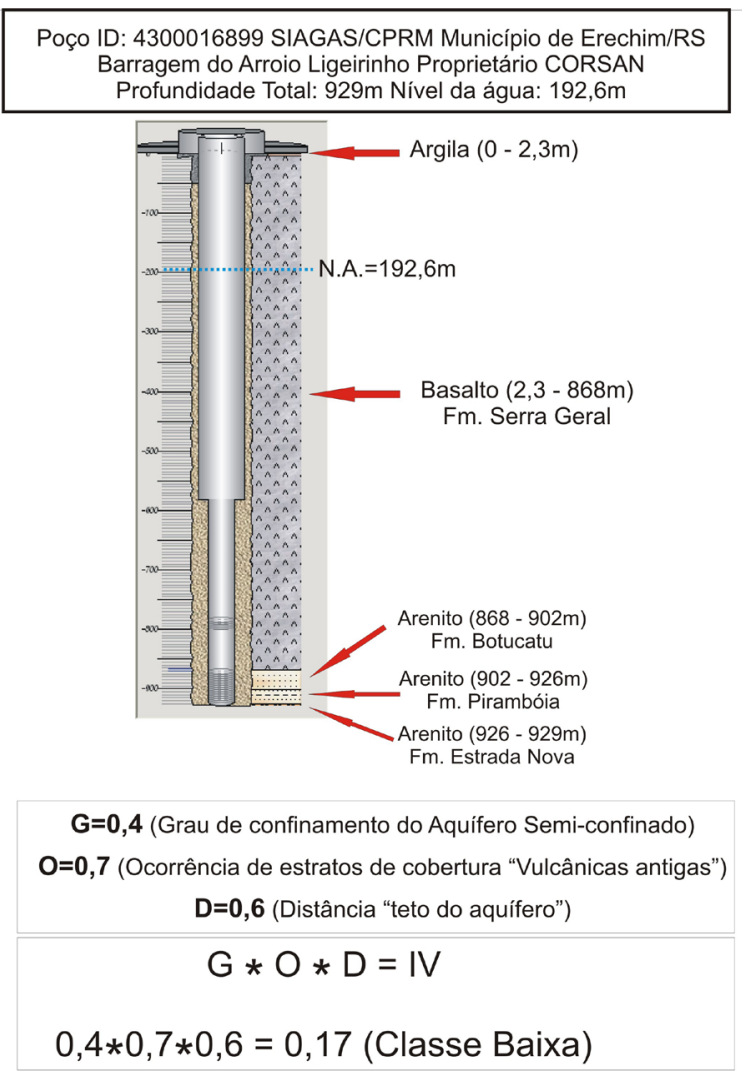

Figura 5 - Exemplo de aplicação do sistema GOD em poço tubular. Fonte BRASIL/CPRM/SIAGAS (www.cprm.gov.br/ siagas).

O Quadro 1 ilustra os intervalos das classes de vulnerabilidade à contaminação do aquífero: insignificante, baixa, média, alta e extrema e suas respectivas cores utilizadas nesta pesquisa na confecção do mapa do índice de vulnerabilidade.

Quadro 1 - Intervalos de vulnerabilidade da metodologia GOD.

\begin{tabular}{|c|c|c|}
\hline Índice de Vulnerabilidade & \multicolumn{1}{l|}{ intervalos } & Cor \\
\hline Insignificante & $0,0-0,1$ & Branca \\
\hline Baixa & $0,1-0,3$ & Verde \\
\hline Média & $0,3-0,5$ & Amarela \\
\hline Alta & $0,5-0,7$ & Não observada \\
\hline Extrema & $0,7-1,0$ & Não observada \\
\hline
\end{tabular}


Os dados referentes às coordenadas Universal Transversa de Mercator (UTM) e os índices obtidos foram dispostos numa planilha Microsoft Excel 2003. No programa Surfer 8.0, foram gerados os cartogramas pelo método de interpolação Krigagem. Posteriormente, foi realizada a análise da tendência do fluxo subterrâneo através da relação entre a cota altimétrica obtida na boca do poço e o nível da água. Espacializou-se, também, a vulnerabilidade do aquífero à contaminação.

Foram selecionadas 55 captações de um total de 99 poços cadastrados no BRASIL/SIAGAS/CPRM (2010). Procedeu-se uma avaliação da consistência: notando-se que nem todos os poços contavam com informações completas. Destes, cerca de 40 poços não apresentavam o perfil geológico e/ ou informações referentes ao nível estático, condições necessárias para a aplicação do método GOD.

A espacialização da potenciometria e da vulnerabilidade à contaminação do aquífero foi realizada nos Programas SURFER 8.0 e ArcGIS 9.3. Considerou-se a área limite do município de Erechim disponível no sítio do (BRASIL/MPOG/ IBGE, 2010).

\section{Resultados e discussão}

Os resultados referem-se aos 55 poços cadastrados disponíveis no (BRASIL/SIAGAS/CPRM, 2010), localizados na área do município de Erechim/ RS. Estes poços selecionados foram utilizados para aplicar o método GOD para a avaliação do aquífero à contaminação (FOSTER et al., 2006).

A Figura 6 ilustra a espacialização do índice de vulnerabilidade do SASG à contaminação. Foram encontrados 47 poços na classe de vulnerabilidade média, pois apresentaram valores de índice de vulnerabilidade variando entre 0,3 a 0,5 , representando $85,5 \%$ da total do Município (Figura 4), considerando-se os limites municipais disponíveis em (BRASIL/MPOG/IBGE, 2010). A ampla predominância da classe média na área avaliada atrelou-se ao parâmetro "O", Ocorrência Litológica (Figura 4) e pode ser atribuída às características litológicas homogêneas associadas a rochas vulcânicas antigas, maciças, pouco fraturadas e pertencentes a fácies Paranapanema (BRASIL/CPRM, 2008). Nesta classe, incluiu-se a maior parcela da mancha urbana municipal (Figura 6), incluindo-se nessa classe a área de 100 ha do Distrito Industrial Irani Jaime Farina, onde estão instaladas 34 empresas (http:// www.pmerechim.rs.gov.br). Neste trecho da Bacia do Paraná, ocorrem afloramentos de derrames de rochas vulcânicas que conferem uma condição de confinamento às rochas sedimentares arenosas, e estas ocorrem em profundidade, como nos exemplos dos poços (ID 4300016899) e no (ID 4300013499) no município de Três Arroios (BRASIL/CPRM/ SIAGAS, 2010). Observando-se a espessura dos solos, notou-se uma variação de profundidade entre 0,6 até $19,6 \mathrm{~m}$ associada a esta classe.

Na classe baixa, inseriram-se 7 poços, os quais representam $12,7 \%$ da área avaliada e distribuem-se preferencialmente na porção centro-leste da carta de vulnerabilidade Figura 6. A espessura dos solos apresentou uma ampla faixa de variação entre 2,9 a $27,6 \mathrm{~m}$, porém foi associada a uma textura predominantemente argilosa a siltosa, o que conferem aos solos uma condição de menor permeabilidade, logo de menor risco potencial à contaminação. $\mathrm{Na}$ classe de vulnerabilidade insignificante, foi considerado apenas o poço (ID4300017760), este foi único poço penetrado diretamente em rocha vulcânica sã. Esta ocorrência representa apenas $1,8 \%$ dos 55 poços (Figura 6). Sua localização está

Quadro 2 - Distribuição espacial das classes de vulnerabilidade na área em estudo incluindo-se proposta de distribuição das atividades associadas a vulnerabilidade.

\begin{tabular}{|c|c|c|c|c|c|c|}
\hline \multirow[b]{2}{*}{ Classe } & \multicolumn{2}{|c|}{ Município (Urbano+Rural) } & \multicolumn{2}{|c|}{ Urbano } & \multirow{2}{*}{$\begin{array}{c}\text { Atividade } \\
\text { Potencial poluidor }\end{array}$} & \multirow{2}{*}{$\begin{array}{c}\text { Classe de } \\
\text { vulnerabilidade à } \\
\text { contaminação }\end{array}$} \\
\hline & Área $\left(\mathrm{km}^{2}\right)$ & Perc. (\%) & $\begin{array}{l}\text { Área } \\
\left(\mathrm{km}^{2}\right)\end{array}$ & Perc. (\%) & & \\
\hline Insig. & 0,18 & 0,04 & 0,0 & 0,0 & Alto & Baixa \\
\hline Baixa & 90,76 & 21,08 & 5,3 & 19,9 & Baixa & Média \\
\hline Média & 339,59 & 78,88 & 21,3 & 80,1 & Média & Baixa \\
\hline Total & 430,53 & 100 & 26,6 & 100 & & \\
\hline
\end{tabular}


na porção leste em cota altimétrica da ordem de $523 \mathrm{~m}$, apresentando um nível da água profundo, da ordem de $150 \mathrm{~m}$.

No Quadro 2, estão apresentados os percentuais de áreas ocupadas pelas três classes de vulnerabilidade à contaminação do Sistema Aquífero Serra Geral (insignificante, baixa e média) para o município de Erechim. Propõe-se para o Plano Diretor de ocupação dos espaços futuros do crescimento urbano que, para o licenciamento e implantação de empreendimentos potencialmente poluidores considerados Alto como os entrepostos de suínos, sejam associados às áreas de vulnerabilidade baixa, já as áreas destinadas à mineração das substâncias tais como: basaltos saibro e argilas, com um potencial poluidor médio, sejam associadas à classe média vulnerabilidade. Enquanto que as atividades de potencial poluidor baixo, como lavagem de veículos, sejam implantadas em áreas com classe de vulnerabilidade média.

Ainda observando a Figura 6, nota-se que na mancha urbana predominou a classe de vulnerabi- lidade média, o que não indica ser área apropriada para disposição de resíduos sólidos e/ou outros tipos de depósitos potencialmente contaminantes como cemitérios Resoluções CONAMA n ${ }^{\circ}(335 / 2003$ e 368/2006), postos de combustíveis Resoluções CONAMA n ${ }^{\circ}(273 / 2000,313 / 2002$ e 319/2002), sem tratamento adequado e ainda, dispondo de poços de monitoramento de nível de água e de contaminação.

Machado e Freitas (2005) sugerem que o SASG I esteja enquadrado na classe de vulnerabilidade alta a média à contaminação. Estudos de escala local indicaram predominância da classe baixa e média.

Pode-se dizer que as condições locais do SASG, constituídos por solos e/ou rochas vulcânicas e seus produtos de alteração (Neossolos Litólicos), são adequadas para uso e ocupação dos solos (BRASIL/Lei no 6.766/1979). Porém, convém ressaltar que não deve ser permitido o parcelamento do solo: Art. $3^{\circ}$, IV - em terrenos onde as condições geológicas não aconselham

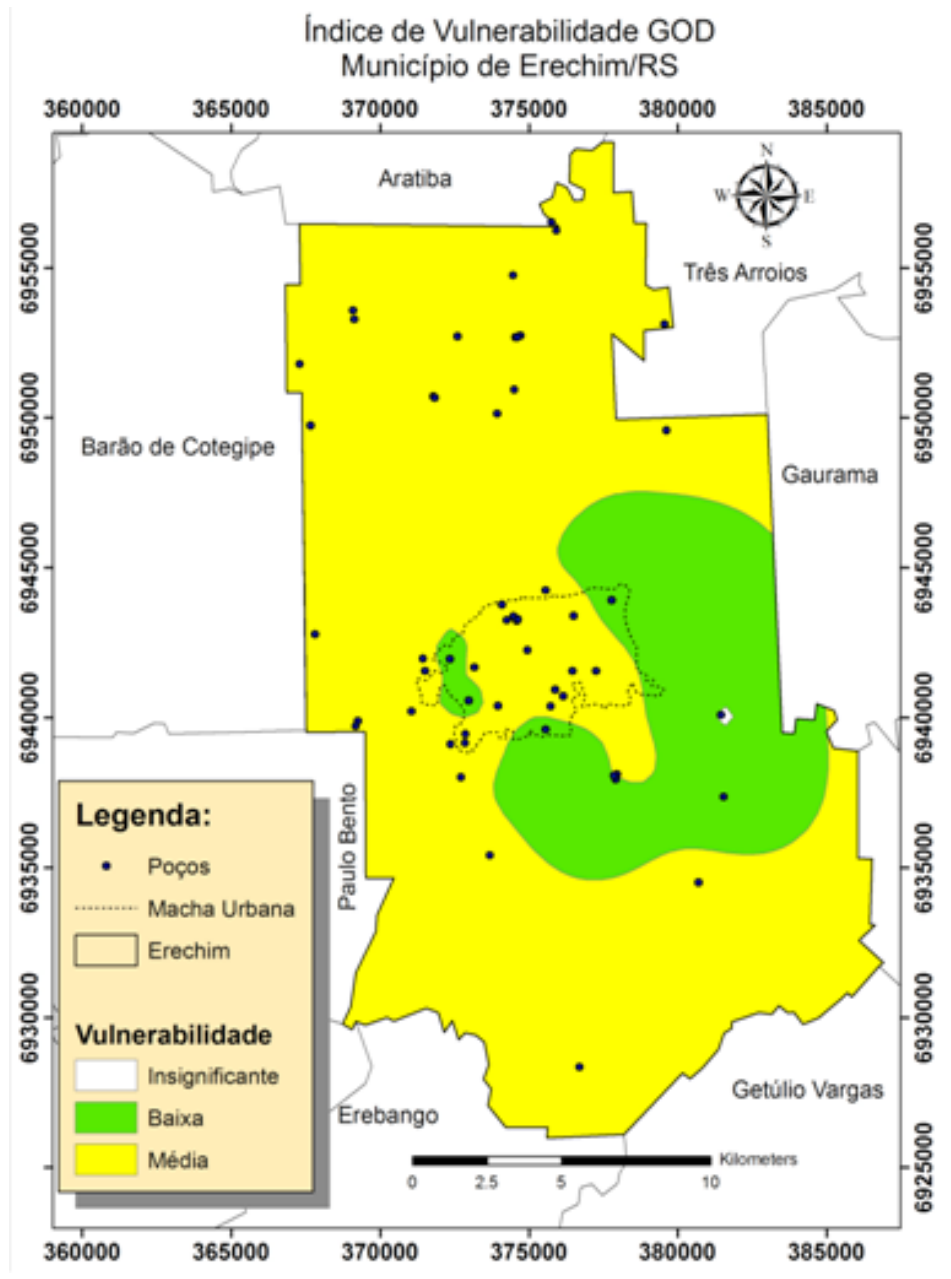

Figura 6 - Carta do Índice de Vulnerabilidade do aquífero Serra Geral à contaminação, Município de Erechim, RS. 
a edificação sem que sejam tomados os devidos cuidados na disposição dos efluentes, bem como efetivada a coleta e o tratamento dos esgotos, ainda deficiente no Município avaliado.

Os gradientes potenciométricos (Figura 7), supondo-se que as fraturas das rochas vulcânicas estejam conectadas, indicaram uma variação da ordem de 364 metros (416 a 780 metros) em relação ao nível médio do mar. O fluxo regional indicou uma tendência principal predominante em sentido sudeste e nordeste, drenado pelo Rio Dourado Figura 1, inserido na Depressão Potenciométrica Regional (situada ao norte do cartograma). A estimativa da cota potenciométrica é importante, pois a mesma indica a provável direção do fluxo subterrâneo associada à dispersão dos contaminantes. Supondo-se que as fraturas das rochas vulcânicas estejam conectadas hidraulicamente, podendo, assim, atingir o aquífero fraturado e sofrer dispersão Figura 3.

Estudos anteriores em escala de menor detalhe (ARAÚJO et al., 1995; CAMPOS, 2000), em nível da Bacia do Paraná, indicaram para a região hidrográfica do Uruguai cotas potenciométricas superiores a 1.000 até inferiores a $200 \mathrm{~m}$. Esses autores encontraram baixos potenciométricos tanto ao longo dos rios Pelotas-Uruguai e Paraná, indicando descargas locais ao longo dos cursos dos rios. Já (CAMPOS, 2000) para a região de Erechim, estimou-se linhas piezométricas da ordem de $350 \mathrm{~m}$ e a direção de fluxo regional sudeste para noroeste. Já os estudos desenvolvidos em escala de maior detalhe, incluindo diversas informações de captações cadastradas no município de Erechim, possibilitaram a obtenção de tendências regionais em direção sudeste e nordeste associadas às variações do relevo local.

De acordo com MACHADO e FREITAS (2005), as capacidades específicas do Sistema Aquífero Serra Geral são muito variáveis, existindo poços produtivos próximos de outros com excelentes vazões. Observou-se que a capacidade específica de cerca de 40 poços variou entre 0,01 até 3,2 $\mathrm{m}^{3} / \mathrm{h} / \mathrm{m}$ e apenas no poço (ID 4300017761) supe-

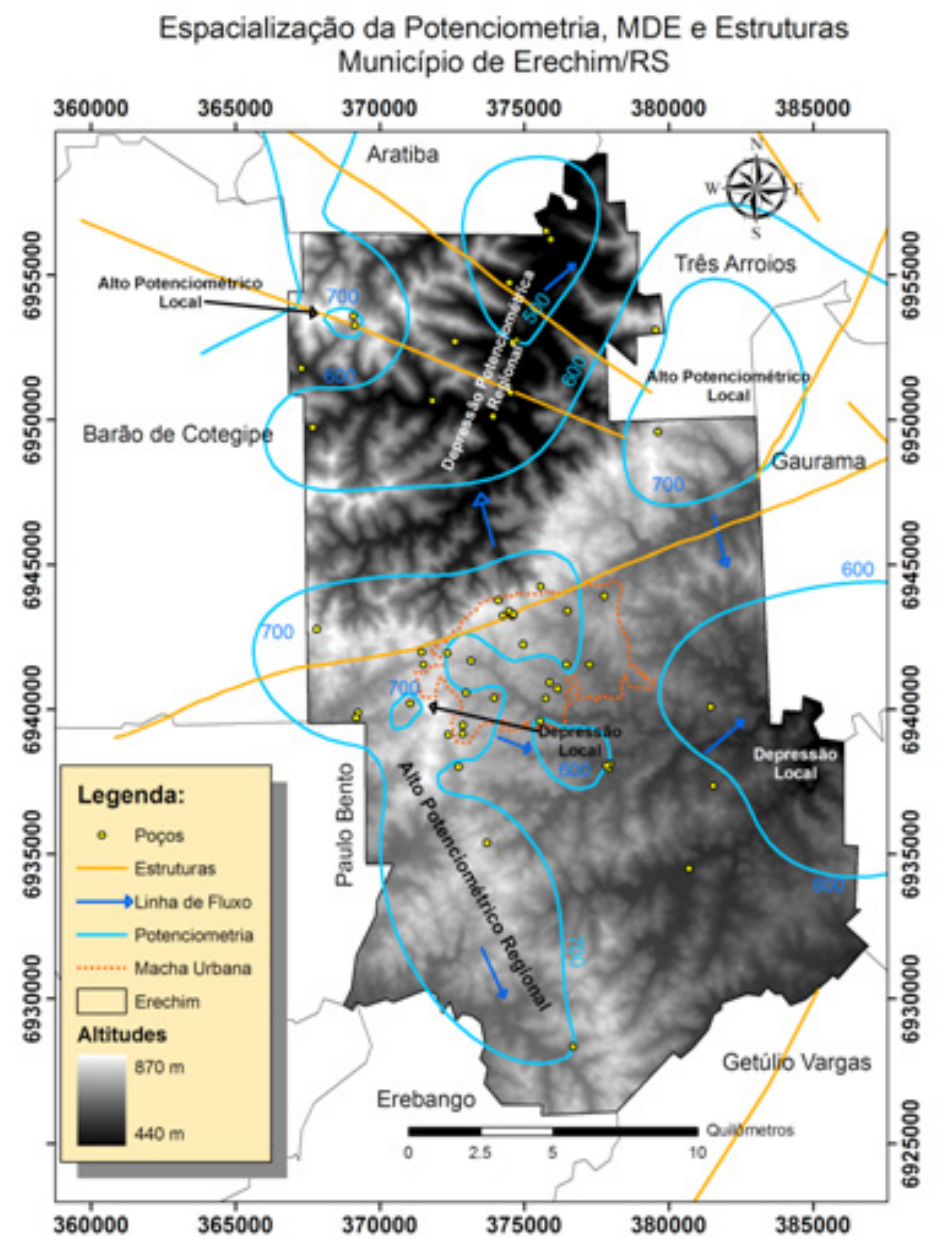

Figura 7 - Espacialização do Modelo Digital de Elevação, Estruturas e a potenciometria em SIG. Erechim/RS. 
rou os $4 \mathrm{~m}^{3} / \mathrm{h} / \mathrm{m}$, confirmando as observações de MACHADO e FREITAS (2005) que consideraram o SASG I como aquífero fraturado de alta a média produtividade.

$\mathrm{Na}$ Figura 7, em escala regional, ocorre a formação de um alto potenciométrico na porção oeste e sudoeste do mapa que contribui para o Rio Cravo. Ocorrem várias depressões potenciométricas locais, sendo que uma delas coincide com a ETA da CORSAN, próximo da mancha urbana (Figuras 6 e 7). Na porção norte, forma-se uma depressão potenciométrica regional, onde as linhas de fluxo tendem para nordeste e noroeste e contribuem para a perenização do Arroio Paca, Rio Negro e Rio Dourado, afluentes da margem esquerda do Rio Uruguai, próximo do município de Aratiba/RS. No sudeste do mapa, observa-se um fluxo de direção nordeste e contribui para a perenização do Arroio Tigre no município de Gaurama.

Nanni et al. (2005) avaliaram os aspectos de vulnerabilidade natural associados ao risco de contaminação do Aquífero Serra Geral na Região Hidrográfica do Rio Uruguai SEMA (2004). Concluíram que nos mapas de vulnerabilidade dos recursos hídricos subterrâneos à contaminação:

as áreas com baixa vulnerabilidade à contaminação estão sobretudo vinculadas as regiões de cabeceiras dos cursos de água principais e dos tributários. Essa característica tem relação direta com a maior espessura dos solos e a condição mais suave das declividades, ambos condicionados a menor presença de fraturas em meio subterrâneo;

as áreas de média vulnerabilidade ocorrem ao longo dos vales dos cursos principais, aumentando na direção de sua foz;

as áreas com alta vulnerabilidade ficaram restritas ao eixo daquelas drenagens que estão condicionadas por fraturas ou a uma concentração de cruzamentos dessas.

Comparando-se os resultados obtidos para as Bacias U10 e U20 Figura 1, pode-se dizer que:

A classe baixa coincidiu com a maior amplitude de variação da espessura dos solos (zona vadosa);

A classe média relacionou-se com áreas de relevo plano e/ou pouco movimentadas, incluindo-se interflúvios e vales de direção preferencial nordeste associados aos cursos de água dos rios Dourado, Campo, Cravo e Lageado Paca, enquanto que o Rio Negro encaixou-se em vales de direção oeste/ leste Figuras 1, 6 e 7. Observou-se uma faixa de amplitude menor de espessura de solos;

$\mathrm{Na}$ área do estudo no município de Erechim, não se observou a classe alta de vulnerabilidade;

\section{Conclusóes}

$\mathrm{Na}$ área de estudo, o Aquífero Serra Geral/ SASG apresentou uma predominância da classe de vulnerabilidade média a contaminação, representando $85,5 \%$ da área do município. Este fato sugere cuidados no uso e ocupação dos solos tanto na área rural, onde predominam cultivos diversos, como na mancha urbana, de uso antrópico.

$\mathrm{O}$ índice de vulnerabilidade insignificante e baixo do aquífero à contaminação ocuparam respectivamente $0,04 \%$ e $21,08 \%$. Houve uma ampla predominância da classe média com $78,88 \%$ da área avaliada. Devem-se principalmente ao tipo de litologia predominante na área composto por rochas vulcânicas pertencentes á Formação Serra Geral, Fácies Paranapanema (constituído por lavas básicas e/ou seus produtos de intemperização), formando um aquífero que apresenta porosidade predominantemente por fraturas. Este tipo litológico, (caso as fraturas estejam conectadas) pode, localmente facilitar o caminho das águas que venham infiltrar no sistema solo-subsolo-rocha-aquífero o que eleva seu risco de alteração de sua qualidade natural.

Deve-se destacar que as conclusões obtidas com as ferramentas de geoprocessamento deveriam ser utilizadas no plano diretor Municipal. Regionalmente, verificou-se uma tendência do fluxo subterrâneo da água ser predominante em sentido sudeste/nordeste. A espessura da zona vadosa e também a indicação dos fluxos subterrâneos servem de subsídios na locação de futuros empreendimentos que utilizem o subsolo para a disposição de efluentes, destacando-se: os cemitérios, os postos de combustíveis e as áreas destinadas à mineração. Uma vez que estas atividades são potenciais poluidoras das águas subterrâneas e, ainda, necessitam uma adequada gestão, a qual deve ser considerada nas políticas públicas de uso e ocupação do solo em escala municipal.

\section{REFERÊNCIAS}

ALBINET, M. e MARGAT, J. Cartographie de la vulnérabilité à la pollution des nappes d'eau souterraine. Bull BRGM 2me Series 3(4):13-22. 1970.

ALLER, L.; T. BENNET, J. LEHR; PETTY, R.; e HACKETT, G.: DRASTIC: A Standardized System for Evaluating Groundwater Pollution Potential Using Hydrogeologic Setting. National Water Well Association. Dublin Ohio. EPA, Oklahoma. USA, EPA-600/2-87-035. 1987. 
ARAÚJO, L. M.; FRANÇA, A. B.; POTTER, P. E. Aquífero Gigante do MERCOSUL no Brasil, Argentina, Paraguai e Uruguai: Mapas Hidrogeológicos das Formações Botucatu, Pirambóia, Rosário do Sul, Buena Vista, Misiones e Tacuarembó. UFPR, PETROBRÁS. 1995.

\section{BRASIL/COMPANHIA DE PESQUISA E} RECURSOS MINERAIS, CPRM. Mapa de Domínios e Subdomínios Hidrogeológicos do Brasil. Escala 1:2.500.000. CPRM, 1 CD - ROM. 2007.

\section{BRASIL/COMPANHIA DE PESQUISA DE} RECURSOS MINERAIS, CPRM. Mapa Geológico do Estado do Rio Grande do Sul. Escala 1:750.000. CPRM, 1 CD - ROM. 2008.

\section{BRASIL/COMPANHIA DE PESQUISA DE} RECURSOS MINERAIS, CPRM/ SIAGAS. Disponível em: <http://www.siagas.cprm.gov.br>. Acesso em: 15 fev. 2010.

\section{BRASIL/DEPARTAMENTO NACIONAL DA PRODUÇÃO MINERAL/DNPM. SISTEMA DE INFORMÇÃO HIDROGEOLÓGICA/SIGHIDRO. Disponível em: <http:// www.dnpm. gov.br/ sighidro>. Acesso em: 05 jan. 2010.}

\section{BRASIL/INSTITUTO BRASILEIRO DE} GEOGRAFIA E ESTATISTICA IBGE. Mapa de Climas do Brasil. Disponível em: <http:// www. ibge.gov.br/ home/ geociencias/default_prod.shtm>. Acesso em: 12 dez. 2009. 2002.

\section{BRASIL/INSTITUTO BRASILEIRO DE GEOGRAFIA E ESTATISTICA/IBGE. Cidades@. Disponível em:}

$<$ http://www.ibge.gov.br/cidadesat/topwindow. htm?1>. Acesso em: 10 fev. 2010.

BRASIL. LEI No 6.766, de 19 dezembro de 1979. "Dispõe sobre o parcelamento do solo urbano e dá outras providências". Loteamento e parcelamento do solo. Série Legislação Brasileira. org. Juarez de Oliveira. Editora Saraiva. p. 41-55. 1979.

BRASIL. Resolução CONAMA n 273 de 29 de novembro 2000. Disponível em: <http://www.mma. gov. br/port/conama/res/res00/res27300.html>. Acesso em: 12 maio 2008.

BRASIL. Resolução CONAMA N ${ }^{\circ} 313$, de 29 de outubro de 2002. "Dispõe sobre o Inventário
Nacional de Resíduos Sólidos Industriais". Disponível em: < http://www.mma.gov.br/port/ conama/legiabre. fm?codlegi $=335>$. Acesso em: 10 mai. 2010.

BRASIL. Resolução CONAMA N 319, de 04 de dezembro de 2002. "Dá nova redação a dispositivos da Resolução CONAMA N 273, de 29 de novembro de 2000, que dispõe sobre prevenção e controle da poluição em postos de combustíveis e serviços". Disponível em: < http://www. mma. gov.br/port/conama/legiabre.cfm?codlegi $=341>$. Acesso em: 10 maio 2010.

BRASIL. Resolução CONAMA N 335, de 03 de abril de 2003. "Dispõe sobre o licenciamento ambiental de cemitérios". Disponível em: http:// www.mma.gov.br/ port/conama/legiabre. cfm?codlegi=359. Acesso em: 10 mai. 2010.

BRASIL. Portaria N $\mathrm{N}^{\circ}$ 518, de 25 março de 2004. "Estabelece os procedimentos e responsabilidades relativos ao controle e vigilância da qualidade da água para consumo humano e seu padrão de potabilidade, e dá outras providências". Disponível em <http://bvsms.saude.gov.br/bvs/ publicacoes/ portaria_518_2004.pdf>. Acesso em: 03 fev. 2010.

BRASIL. Resolução CONAMA N 368, de 28 de março de 2006. "Altera dispositivos da Resolução $\mathrm{N}^{\circ} 335$, de 3 de abril de 2003, que dispõe sobre o licenciamento ambiental de cemitérios". Disponível em: < http://www.mma. .gov.br/port/conama/ legiabre.cfm?codlegi=488>. Acesso em: 10 mai. 2010.

CAMPOS, H. C. N S. Mapa hidrogeológico do Aquífero Guarani. UNISINOS, São Leopoldo. Escala de 1:2.500.000. 2000.

CIVITA, M.; Assesment of aquifer vulnerability to contamination. "Protezione e Gestione delle Acque Sotteranee Mettodologie, Technologie e Obbietivi". Marano sul Panaro, v.3, p.39-86. 1990.

CREA-RS, Mitos e verdades do Aquífero Guarani. CONSELHO EM REVISTA N 10. Ano I. Porto Alegre: Junho de 2005. 11-13p.

CRUZ, J.C.; CRUZ, R. C.; NUMMER, A. V.; ELTZ, F.L.F.; SILVÉRIO DA SILVA, J.L.; SILVEIRA, G. L.; ARAUJO, T. A. Desenvolvimento metodológico e tecnológico para avaliação ambiental integrada aplicada ao processo de viabilidade de hidrelétricas. 
Relatório parcial do projeto FRAG-RIO entre UNIPAMPA/UFSM/ MMA, 1, 285 p. CD-ROM. 2010.

CRUZ, J. C.; NUMMER, A. V.; ELTZ, F.L.F.; SILVÉRIO DA SILVA, J.L.; ARAUJO, T. A. Avaliação Ambiental Integrada: Construção Metodológica de Modelo par Bloco do Meio Físico. Revista Brasileira de Recursos Hídricos, volume 18, n.1-Jan/Mar 2013, 223-233.

ESRI Portugal. Sistemas e Informação Geográfica. ArcGIS 9.3. Disponível em: <http://www. esriportugal.pt/noticias /341-arcgis-931-novidades. html>. Acesso em: 03 maio 2010.

\section{ESTADO DO RIO GRANDE DO SUL/SEMA,} Secretaria Estadual do Meio Ambiente. DRH, Departamento de Recursos Hídricos, Mapa do Rio Grande do Sul, Divisão Municipal e Bacias Hidrográficas. SEMA/DRH: Fevereiro de 2004.

\section{ESTADO DO RIO GRANDE DO SUL/SEMA.}

Limite das bacias hidrográficas para visualização no google earth. Disponível em: <http://www.sema. rs.gov.br/sema $/ \mathrm{html} / \mathrm{rhgoo} . \mathrm{htm}>$. Acesso em: 12 de maio de 2010. 2004.

FOSTER, S. S. D.; "Fundamental concepts in aquifer vulnerability pollution risk and protection strategy". Proceedings of International Conference: Vulnerability of Soil and Groundwater to Pollutants. Noordwijk, Países Baixos. 1987.

FOSTER, S. S. D. e HIRATA, R. C. A.; Groundwater pollution risk assessment: a methodology based on available data. CEPIS/PAHO Technical Report. Lima, Peru. 1988.

FOSTER, S.S.D. e HIRATA, R. C. A.; Determinação do risco de contaminação das águas subterrâneas: um método baseado em dados existentes. São Paulo: Instituto Geológico. Boletim N. ${ }^{\circ} 10.1993$.

FOSTER, S. S. D.; HIRATA, R. C. A.; GOMES, D.; D'ELIA, M.; PARIS, M.; Proteção da Qualidade da Água Subterrânea: um guia para empresas de abastecimento de água, órgãos municipais e agências ambientais. Groundwater Management Advisory GW. MATE WB. 2006.

GOLDEN SOFTWARE. Surfer version 8.0: surface mapping system. Colorado, USA: 1 CD-Rom. 2002.
HASSUDA, S.; Água subterrânea: um recurso a proteger - In. Ciências da Terra e Meio Ambiente Diálogos para (inter)ações no Planeta. São Leopoldo: UNISINOS. 1999.

HAUSMAN, A. Comportamento do Freático nas Áreas Basálticas do Rio Grande do Sul. Boletim Paranaense de Geografia, n.18/20, 1966. 215 p.

HAUSMAN, A. Províncias Hidrogeológicas do Rio Grande do Sul. Acta Geológica Leopoldensia. Universidade do Vale do Rio dos Sinos, 1995. 125p.

HEATH, C. R. Hidrologia Básica de Águas Subterrâneas. Tradução de Mário Wrege e Paul Potter. Porto Alegre: Ed. UFRGS. Título original: United States Geological Survey, Water Supply Paper 2220. 1983. 84p.

LANDIM, P. M. B.; Introdução aos métodos de estimação espacial para confecção de mapas. DGA, IGCE, UNESP/Rio Claro, Lab. Geomatemática, Textos Didático 02. Disponível em: <http://www. rc.unesp. br/igce/aplicada /textodi.html>. Acesso em: 16 abr. 2010. 2000. 20p.

LANDIM, P. M. B.; QUEIROZ, J. C. B. Análise estatística de dados geológicos multivariados: exercícios resolvidos. DGA, IGCE, UNESP/Rio Claro, Lab. Geomatemática, Textos Didáticos 04. Disponível em: <http://www.rc.unesp. br/igce/ aplicada/>. Acesso em: 16 abr. 2010. 2000. 44p.

LANDIM, P. M. B.; MONTEIRO, R. C.; CORSI, A. C.; Introdução à confecção de mapas pelo software Surfer. Geomatemática, Texto Didático 8, DGA,IGCE,UNESP/Rio Claro. Disponível em: < http://www.rc.unesp.br/igce/aplicada/ DIDATICOS/ LANDIM/Surfer. pdf $>$. Acesso em: 16 abr. 2010. 2002.

LANDIM, P. M. B.; STURARO, J. R.; Krigagem Indicativa aplicada à elaboração de mapas probabilísticos de riscos. Geomatemática. Texto Didático 6, DGA,IGCE,UNESP/Rio Claro. Disponível em <http://www.rc.unesp.br/igce/ aplicada/textodi.html> .Acesso em: 16 abr. 2010. 2002.

LE GRAND, H. System for evaluating contamination potential for some waste sites. American Water Work Association Journal. v. 56, n. 8, 1964. p. 959-974. 
LLERA, J. M. P. y AZCOITI, J. M. F.; CAMBIO CLIMÁTICO y AGUA SUBTERRÁNEA. Visión para los próximos decenios. Madrid: Instituto Geológico y Minero de España, ed. 556:504. 2008.

MOCELLIN, R. C. e FERREIRA, J. F. F.; Conectividade e compartimentação dos sistemas aquíferos Serra Geral e Guarani no sudoeste do estado do Paraná, Brasil. Revista Brasileira de Geociências (RBG). v.39, n³, 2009, pp.567-579. Disponível em: <http://ojs.c3sl.ufpr.br/ojs2/index. $\mathrm{php} / \mathrm{rbg} / \mathrm{rticle} /$ viewFile/14146/11177>.Acesso em: 22 abr. 2010.

MACHADO, J. L. F. e FREITAS, M. A. de; Projeto Mapa Hidrogeológico do Rio Grande do Sul: relatório final. Porto Alegre: CPRM, 2005, 65p.: Il.

MACIEL FILHO, C. L.; SILVÉRIO DA SILVA, J.L. ARAUJO, T. A.. Aspectos geológicos para inventário cap.6, p.215-247. Org. CRUZ, J.C.; SILVEIRA, G.L. Seleção Ambiental de Barragens: Análise de favorabilidades ambientais em escala de Bacia Hidrográfica. Editora da UFSM/ABRH, 2005, p.388.

MARGAT, J. Groundwater vulnerability to contamination. BRGM, 68 sgl 198, HYD, Orleans, France. 1968.

NANNI, A. S.; TEDESCO, M. A.; FREITAS, M. A.; BINOTTO, R. B. Vulnerabilidade natural e risco de contaminação do Aquífero Serra Geral pela suinocultura na Região das Missões - RS. IN XVI Simpósio Brasileiro de Recursos Hídricos. 2005. Disponível em: <http://www.dpi. inpe.br/spring/ português/arquivos_publicacoes/xvi_sbrh.pdf. Acesso em 17 jan. 2010.

ORTEGA, R. M. V. y MIRANDA, V. R.; Vulnerabilidad a la Contaminación de las Águas Subterráneas en los Acuíferos Cubanos. IV Seminario-taller. Protección de Acuíferos Frente a la Contaminación: Protección de la Calidad del Água Lima, Perú, Abril. 2004.

PIRAN, N.; "Contribuição ao Estudo do Clima de Erexim-RS". Dissertação de Mestrado. Rio Claro: IGCE/UNESP. 1982.

RAMPAZZO, S. E., Proposta conceitual de zoneamento ambiental para o município de Erechim (RS). Tese de Doutorado - Universidade Federal de São Carlos, São Carlos: UFSCar. 2003. 177p.
REBOUÇAS A.C. e FRAGA C.G.; Hidrogeologia das rochas vulcânicas do Brasil. Revista de Águas Subterrâneas, v.12. 1988. p.29-55.

RONEN, D.; SCHER, H.; BLUNT, M., "Field observations of a capillary fringe before and after a rainy season. Journal of Contaminant Hydrology". Elsevier, v. 44. Disponível em: < http://www. elsevier. com/wps/find/journal description.cws_ home/503341/description\#description > .Acesso em: 02 fev. 2010. 2000.

RONEN, D.; GRABER, E. R.; LAOR, Y. "Volatile Organic Compounds in the Saturated-Unsaturated Interface Region of a Contaminated Phreatic Aquifer". Vadose Zone Journal. Madison/USA. Disponível em:< http://vzj. scijournals.org/cgi/ content/abstract $/ 4 / 2 / 337>$. Acesso em: 22 outubro de 2009. 2005.

SILVÉRIO DA SILVA, J. L.; DRESSLER, V. L.; RIFFEL, E. S.; SANTIAGO, M. R. Ocorrências anômalas de flúor em águas subterrâneas do Sistema Aquífero Guarani no Estado do Rio Grande do Sul. IN: V Seminário Latino-Americano e I IberoAmericano de Geografia Física. Santa Maria-RS. 2008.

STRECK, E. V.; KAMPF, N.; DALMOLIN, R. S. D.; KLAMT, E.; NASCIMENTO, P. C. do; SCHNEIDER, P.; GIASSON, E.; PINTO, L. F. S.; Solos do Rio Grande do Sul. 2a . Ed. rev. e ampl. Porto Alegre: EMATER/RS - ASCAR. 2008. 222p.

Van STEMPVOORT, D. and EWERT, L. AVI: A method for groundwater protection mapping in the Prairie, Provinces of Canada. Saskatchewan. 1994.

ZINGANO, A.; Surfer para windows - guia de consulta, Universidade Federal do Rio Grande do Sul/UFRGS. Departamento de Engenharia de Minas - Laboratório de Pesquisa Mineral e Planejamento Mineiro/lpm. 2005. 21 p. impresso. 